\title{
Effect of ZSM-5 acidity on aromatic product selectivity during upgrading of pine pyrolysis vapors
}

\author{
Chaiwat Engtrakul $^{\mathrm{a}}$, Calvin Mukarakate ${ }^{\mathrm{b}}$, Anne K. Starace ${ }^{\mathrm{b}}$, Kimberly A. Magrini ${ }^{\mathrm{b}}$, \\ Allyson K. Rogers ${ }^{\mathrm{b}}$, and Matthew M. Yung*b \\ ${ }^{a}$ Chemistry and Nanoscience Center, National Renewable Energy Laboratory, 15013 Denver West Pkwy, \\ Golden, CO, 80401 USA \\ ${ }^{\mathrm{b}}$ National Bioenergy Center, National Renewable Energy Laboratory, 15013 Denver West Pkwy, Golden, \\ CO, 80401 USA \\ *Corresponding Author: Matthew.Yung@nrel.gov; Fax: 1-303-384-6363; Phone: 1-303-384-7771 \\ Author email addresses: Chaiwat Engtrakul: Chaiwat.Engtrakul@nrel.gov \\ Calvin Mukarakate: Calvin.Mukarakate@nrel.gov \\ Anne Starace: Anne.Starace@nrel.gov \\ Kim Magrini: Kim.Magrini@nrel.gov \\ Allyson Rogers: rogers.allysonk@gmail.com
}

\begin{abstract}
The impact of catalyst acidity on the selectivity of upgraded biomass pyrolysis products was studied by passing pine pyrolysis vapors over five ZSM-5 catalysts of varying acidity at $500^{\circ} \mathrm{C}$. The $\mathrm{SiO}_{2}$-to- $\mathrm{Al}_{2} \mathrm{O}_{3}$ ratio (SAR) of the $\mathrm{ZSM}-5$ zeolite was varied from 23 to 280 to control the acidity of the catalyst and the composition of upgraded products. The upgraded product stream was analyzed by GCMS. Additionally, catalysts were characterized using temperature programmed desorption, diffuse-reflectance FTIR spectroscopy, $\mathrm{N}_{2}$ physisorption, and X-ray diffraction. The results showed that the biomass pyrolysis vapors were highly deoxygenated to form a slate of aromatic hydrocarbons over all of the tested ZSM-5 catalysts. As the overall acidity of the ZSM-5 increased the selectivity towards alkylated (substituted) aromatics (e.g., xylene, dimethylnaphthalene, and methyl-anthracene) decreased while the selectivity towards unsubstituted aromatics (e.g., benzene, naphthalene, and anthracene) increased. Additionally, the selectivity towards polycyclic aromatic compounds (2-ring and 3-ring) increased as catalyst acidity increased, corresponding to a decrease in acid site spacing. The increased selectivity towards less substituted polycyclic aromatic compounds with increasing acidity is related to the relative rates of cyclization and alkylation reactions within the zeolite structure. As the acid site concentration increases and sites become closer to each other, the formation of additional cyclization products occurs at a greater rate than alkylated products. The ability to adjust product selectivity within 1-, 2-, and 3ring aromatic families, as well as the degree of substitution, by varying ZSM-5 acidity could have significant benefits in terms creating a slate of upgraded biomass pyrolysis products to meet specific target market demands.
\end{abstract}

Keywords: biomass, pyrolysis, vapor phase upgrading, acidity, ZSM-5, zeolite

\subsection{Introduction}

One of the essential requirements in developing a low-cost thermochemical process for converting raw biomass into usable hydrocarbon-based chemicals and fuels is 
an efficient and stable catalyst technology. This requirement arises due to the poor quality of pyrolysis bio-oil, which predominantly consists of oxygenated organic compounds [14]. Two main conversion pathways, in situ and ex situ catalytic upgrading of fast pyrolysis products, have been developed to produce higher quality bio-oil [5-7]. In the case of the in situ approach, the catalyst is included within the pyrolyzer to catalytically upgrade the biomass fast pyrolysis vapors. The ex situ approach employs a catalyst immediately following the pyrolyzer and allows for the distinct optimization of the pyrolysis and catalyst performance conditions. Nonetheless, both catalytic vapor phase upgrading (VPU) approaches have been shown to improve the overall quality of the biooil through the catalytic removal of oxygen functionalities in actual process development units $[8,9]$.

Typical vapor phase pyrolysis product deoxygenation reactions are carried out under strongly acidic conditions and elevated temperatures. Catalytic performance (activity, deactivation, and product distribution) is often severely limited at these conditions due to active site poisoning and changes in the pore structure of the catalyst due to coke deposition [10]. Solid acid catalysts such as aluminosilicate zeolites (e.g., ZSM-5, $\beta$-zeolite) have been shown to play a crucial role in the thermochemical conversion of biomass due to their unique structural properties that overcome the challenging barriers associated with producing bio-oil [11]. These types of acid catalysts tend to have desirable physicochemical properties such as strong Brønsted acidity, superior water tolerance, tunable acidity, and high thermal stability, which are all necessary for the production of aromatic hydrocarbons. In addition, the acid sites in aluminosilicate zeolites tend to be reasonably uniform in strength and located in welldefined pore structures resulting in superior performance and stability relative to amorphous acid catalysts. The variation in the $\mathrm{SiO}_{2}$-to- $\mathrm{Al}_{2} \mathrm{O}_{3}$ ratio (SAR) in the zeolite does not affect the overall structure but is expected to affect the acid strength and acid site density, and therefore, control the catalyst activity, deactivation, and product distribution [12]. For example, Ramasamy et al. demonstrated that the conversion of ethanol to various hydrocarbon compounds over ZSM-5 zeolite was dependent on the SAR [13]. The low acid density catalysts (e.g., SAR = 140) tended to deactivate faster and generate more total hydrocarbon compounds (paraffin, olefin, and aromatic) at a similar time-on-stream. The concentration of paraffinic and olefinic compounds generated was higher for the high SAR catalyst and lower for the low SAR catalyst. The low SAR catalyst generated a higher concentration of aromatic compounds primarily due to the high acid strength sites facilitating the dehydrocyclization of paraffins and olefins to aromatics [14]. In another example, Mukarakate et al. upgraded pine pyrolysis vapors using $\beta$-zeolite with widely varying SARs. Here, the authors demonstrated that decreasing the SAR (increasing number of acid sites) led to an increase in the coke deposition and aromatic upgraded vapor yield [15]. These observations were based on real-time compositional analysis of the upgraded pyrolysis vapors using gas chromatography mass spectroscopy (GCMS) and molecular beam mass spectroscopy measurements and similar to those observed by Wan et al. for the conversion of oak pyrolysis vapors over ZSM-5 [16]. The upgraded product distribution from the conversion of pine pyrolysis vapors over ZSM-5 as a function of acid site density has not been fully investigated. 
In this study, we investigated the effect of varying the SAR in the ZSM-5 zeolite on the product distribution during the VPU of pine pyrolysis vapors. A tandem micropyrolyzer connected to a GCMS, in which pulses of pine pyrolysis vapors were upgraded over a series of ZSM-5 (SAR $=23,30,50,80,280)$ catalysts, was utilized to properly identify products and evaluate product yields and distribution as a function of SAR in the catalyst. In a previous study, Mukarakate et al. demonstrated that different levels of deactivation in a ZSM-5 catalyst system was directly related to the biomass-tocatalyst ratio during upgrading of pine pyrolysis vapors [17]. In addition, their results showed that the upgraded product distribution depended on the level of deactivation of the catalyst. Based on these observations, similar reaction conditions and a constant biomass-to-catalyst ratio were utilized in our study to compare catalysts with varying SAR and understand the effect of acid strength and acid site density on the conversion of pine pyrolysis vapors over zeolite catalysts. Temperature programmed desorption of ammonia ( $\mathrm{NH}_{3} \mathrm{TPD}$ ) and in situ diffuse reflectance infrared Fourier transform spectroscopy of pyridine adsorption (pyridine DRIFTS) were utilized to identify the acid sites in the ZSM-5 catalysts.

\subsection{Materials and methods}

\section{$\underline{2.1 \text { Materials }}$}

The five catalysts used in this study were purchased from Alfa-Aesar and consisted of ammonium ZSM-5 zeolites of varying SAR. Prior to their use for upgrading reactions, all of the catalysts were calcined by heating from room temperature to $600^{\circ} \mathrm{C}$ in air at $1 \mathrm{~K} / \mathrm{min}$, and held for 3 hours. The ZSM-5 zeolites (MFI structure) had SAR values of $23,30,50,80$, and 280. X-ray diffraction of the powdered catalysts showed the expected diffraction patterns, with no significant differences amongst the materials, and the average crystallite size of the zeolite phase, as determined by the Scherrer equation was $\sim 25 \mathrm{~nm}+/-5 \mathrm{~nm}$, with no systematic change in crystallite size with varying acidity.

The biomass used for pyrolysis was Southern yellow pine supplied by Idaho National Laboratory and ground into a powder $(120 \mu \mathrm{m})$. Proximate and ultimate analysis, respectively, of the pine powder showed that it contained $2.9 \mathrm{wt} \%$ moisture and elementally consisted of $52 \mathrm{wt} \% \mathrm{C}, 41 \mathrm{wt} \% \mathrm{O}, 6 \mathrm{wt} \% \mathrm{H}$, and $0.01 \mathrm{wt} \% \mathrm{~N}$, with the balance being made up of inorganics, such as calcium, sodium and sulfur.

\section{$\underline{2.2 \text { Catalyst characterization }}$}

\subsubsection{Nitrogen physisorption}

Surface areas were measured using a QuadraSorb S1 surface area and pore size analyzer (Quantachrome Instruments). Samples were set to outgas under vacuum at $250^{\circ} \mathrm{C}$ for $12-24$ hours. For analysis, samples were cooled to $-196^{\circ} \mathrm{C}$ in a liquid nitrogen bath and nitrogen was used as the adsorption gas. Surface areas were calculated using multi-point Brunauer-Emmett-Teller (BET) analysis [18] and pore volumes were calculated using Barrett-Joyner-Halenda (BJH) analysis [19].

\section{$\underline{2.2 .2 \mathrm{NH}_{3}} \underline{T P D}$}


In order to quantify the total number of acid sites on the catalyst materials, $\mathrm{NH}_{3}$ TPD was conducted with the assumed stoichiometry of one $\mathrm{NH}_{3}$ molecule adsorbed per acid site. Catalyst samples (200 mg) were loaded in a quartz U-tube and evaluated on a micro-flow reactor system (AMI-390) equipped with a thermal conductivity detector. Catalysts were pretreated by heating in $10 \% \mathrm{O}_{2} / \mathrm{Ar}$ to $500^{\circ} \mathrm{C}$ and held for $60 \mathrm{~min}$, and then cooled to $120^{\circ} \mathrm{C}$ in He flow. Adsorption consisted of flowing $10 \% \mathrm{NH}_{3} / \mathrm{He}$ for 30 min at $120^{\circ} \mathrm{C}$, followed by flushing with He. The TPD was performed by heating at $30^{\circ} \mathrm{C} / \mathrm{min}$ from $120-500^{\circ} \mathrm{C}$, with a $30 \mathrm{~min}$ hold at $500^{\circ} \mathrm{C}$. The gas flow rate in all steps was $25 \mathrm{sccm}$. A sample loop of known volume was used to calibrate the thermal conductivity detector (TCD) response for $\mathrm{NH}_{3}$, and quantify the amount of $\mathrm{NH}_{3}$ desorbed from the samples. The values for acid site density were calculated by dividing the total acidity by the total BET surface area, and the values for the average acid site spacing assumed an even distribution of the acid sites on a two-dimensional planar surface.

\subsubsection{Pyridine DRIFTS}

Pyridine adsorption experiments were used to probe the nature of acid sites on the catalysts and determine the ratio of Brønsted-to-Lewis acid sites. Since these experiments did not allow for the quantification of the Brønsted and Lewis sites, $\mathrm{NH}_{3}$ TPD was used in conjunction with the pyridine adsorption experiments to quantify the number of each type of acid site. The pyridine adsorption experiments were conducted with a Thermo 6700 FTIR spectrometer with an in situ environmental DRIFTS chamber with a liquid $\mathrm{N}_{2}$ cooled MCT detector. Infrared spectra were obtained from $600-4000 \mathrm{~cm}^{-1}$ at a spacing of $4 \mathrm{~cm}^{-1}$, and 100 scans were taken for both background and sample spectra. Powdered catalyst samples were loaded into the DRIFTS cell and heated to $500^{\circ} \mathrm{C}$ in a flow of 50 $\mathrm{sccm} \mathrm{N}_{2}$ for $\geq 10 \mathrm{~min}$ before background spectra were obtained at $150^{\circ} \mathrm{C}$. Pyridine adsorption was conducted while the catalyst was at $150^{\circ} \mathrm{C}$ by flowing $50 \mathrm{sccm} \mathrm{N} \mathrm{N}_{2}$ through a pyridine bubbler at room temperature for $\sim 15 \mathrm{~min}$., until the sample spectra were observed to remain constant. The catalyst was then flushed with $\mathrm{N}_{2}$ for $15 \mathrm{~min}$. prior to obtaining sample spectra at $150^{\circ} \mathrm{C}$. The pressure throughout the pre-treatment, dosing, and desorption procedures was atmospheric. The intensity of the of the adsorbed pyridine vibrational bands at $1545 \mathrm{~cm}^{-1}$ (Brønsted) and $1455 \mathrm{~cm}^{-1}$ (Lewis) were used to determine the ratio, accounting for their relative molar extinction coefficients $\left(\varepsilon_{\mathrm{B}} / \varepsilon_{\mathrm{L}}=\right.$ 0.76) [20]. The ratios of Brønsted-to-Lewis (B/L) sites were used in conjunction with the total acidity, as determined by $\mathrm{NH}_{3}$ TPD, to calculate the Brønsted and Lewis acidities.

\subsubsection{X-ray diffraction}

Diffraction patterns of catalysts samples were taken on a Rigaku Ultima IV X-ray diffractometer equipped with a copper X-ray source, K-beta filter, and dTex detector. Diffraction patterns were obtained using a data spacing of 0.02 degrees at a scan rate of $2^{\circ}$ two-theta/minute.

\subsection{Pyrolysis and vapor upgrading reaction experiments}

Vapor phase upgrading experiments were conducted using a micro-furnace pyrolyzer (Rx-3050 TR, Frontier Laboratories) with an autosampler coupled to a GCMS. The in-line GCMS allowed for in situ characterization of the vapor phase components. The reactor system consisted of two computer controlled resistively heated elements (hot 
zone). The pyrolysis of the pine samples and catalytic upgrading of the pyrolysis vapors were carried out simultaneously in the hot zone. A trap filled with liquid nitrogen was located after the hot zone to adsorb the upgraded vapors, which were subsequently desorbed to the inlet of the GCMS. For a typical experiment, pine samples $(0.5 \mathrm{mg})$ and catalysts $(10 \mathrm{mg})$ were loaded in stainless steel cups. It should be noted that in these experiments, a high catalyst-to-biomass ratio (20:1) was used in order to help ensure complete conversion of biomass vapors, such that the upgrading reactions were not limited by the number of available active sites and to mitigate the effects of deactivation that might occur. The blank, no catalyst, comparison runs did not contain an inert silica sand, but our previous work has shown no differences in the slate of pyrolysis products obtained over silica sand or through an empty tube [17]. These biomass/catalyst cups were dropped into the hot zone $\left(500^{\circ} \mathrm{C}\right)$ where a He carrier gas was used to sweep the upgraded products from the hot zone to the liquid nitrogen trap. Most of non-condensable light gases passed through the trap, while condensable vapors were collected. The GC set-up did not allow for the separation and quantification of the light gases (e.g., $\mathrm{H}_{2}, \mathrm{H}_{2} \mathrm{O}$, $\mathrm{CH}_{4}, \mathrm{CO}, \mathrm{CO}_{2}, \mathrm{C}_{2}, \mathrm{C}_{3}$ ). The $\mathrm{GC}$ injector was operated at $325^{\circ} \mathrm{C}$ and a constant flow of He was maintained in the capillary column, which utilized a stationary phase consisting of 5\% phenyl and $95 \%$ dimethyl polysiloxane. This column was used to separate the condensable vapors from the upgrading process. The separated upgraded species were identified using the NIST GCMS library. All experiments were conducted in either duplicate or triplicate, and the results were averaged. A schematic of the system and a diagram of the stainless steel cups holding biomass and catalyst are shown in Figure 1.

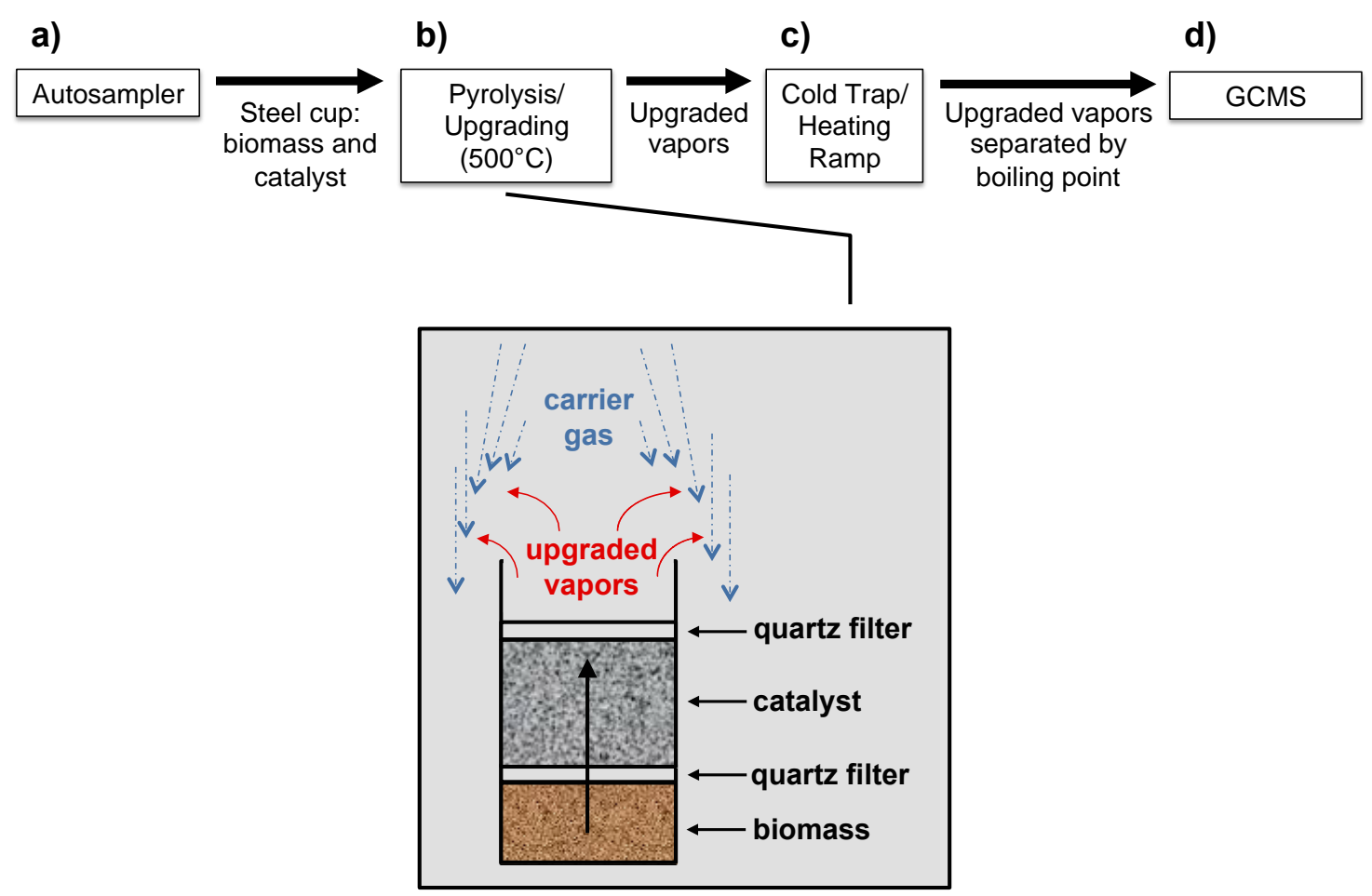

Figure 1. Schematic diagram depicting the reaction and characterization sequence associated with the micro-reactor GCMS unit (a-d). A stainless steel cup was 
utilized to hold biomass and catalyst and configured as shown in the expanded panel.

\subsection{Results and discussion}

\subsection{Catalyst characterization}

The physical properties of the ZSM-5 zeolites of various SARs obtained through $\mathrm{N}_{2}$ physisorption, $\mathrm{NH}_{3}$ TPD, and pyridine DRIFTS, are shown in Table 1. The overall surface area of the materials ranged from $\sim 300-400 \mathrm{~m}^{2} / \mathrm{g}$ and the higher surface area materials generally had a higher pore volume, though these properties did not appear correlated with the SAR. The measured total acidity increased with decreasing SAR, and correlated well to the nominal acidity based on the samples' aluminum content. As the SAR decreased (total acidity increased), the ratio of $\mathrm{B} / \mathrm{L}$ acid sites decreased, which has been previously observed [21]. Datka and Tuznik [22] suggest that the higher B/L ratio on higher SAR zeolites (less acidic) results from an increased stability of the ZSM-5 acid sites and a lower density of acid sites, which makes it more difficult to perform dehydroxylation to form Lewis acid sites during calcination. Since the materials had similar surface areas, as the total acidity increased, the average spacing between acid sites necessarily decreased, ranging from $23.5 \AA$ on the least acidic ZSM-5 to $6.3 \AA$ on the most acidic ZSM-5. The reported average spacing between acid sites did not take into account the type of acid site (i.e., Brønsted or Lewis), but the same trend of decreasing acid site spacing with increasing total acidity is observed if Brønsted-to-Brønsted, Lewisto-Lewis, or Brønsted-to-Lewis distances are calculated.

Table 1. Physical properties of ZSM-5 catalysts used for upgrading pine pyrolysis vapors.

\begin{tabular}{|c|c|c|c|c|c|c|c|c|c|}
\hline $\begin{array}{c}\mathrm{SiO}_{2} / \mathrm{Al}_{2} \mathrm{O}_{3} \\
(\mathrm{SAR})\end{array}$ & $\begin{array}{c}\mathrm{S.A} . \\
\left(\mathrm{m}^{2} / \mathrm{g}\right)^{*}\end{array}$ & $\begin{array}{c}\mathrm{P} . \mathrm{V} . \\
(\mathrm{mL} / \mathrm{g})^{*}\end{array}$ & $\begin{array}{c}\text { Nominal } \\
\mathrm{Al} \\
\text { Content } \\
(\mu \mathrm{mol} / \mathrm{g})\end{array}$ & $\begin{array}{c}\text { Total } \\
\text { Acidity } \\
(\mu \mathrm{mol} / \mathrm{g}) \dagger\end{array}$ & $\begin{array}{c}\text { Brønsted- } \\
\text { to-Lewis } \\
\text { Ratio }\end{array}$ & $\begin{array}{c}\text { Acid Site } \\
\text { Density } \\
\left(\mu \mathrm{mol} / \mathrm{m}^{2}\right)\end{array}$ & $\begin{array}{c}\text { Acid Site } \\
\text { Spacing } \\
(\AA)\end{array}$ & $\mathrm{T}_{1}\left({ }^{\circ} \mathrm{C}\right){ }^{\dagger}$ \\
\hline 23 & 323 & 0.14 & 1350 & 1320 & 2.0 & 4.2 & 6.3 & 280 & 470 \\
\hline 30 & 390 & 0.18 & 1052 & 1120 & 2.4 & 2.7 & 7.8 & 275 & 460 \\
\hline 50 & 375 & 0.16 & 645 & 890 & 3.2 & 1.7 & 9.9 & 260 & 445 \\
\hline 80 & 423 & 0.18 & 408 & 610 & 3.4 & 1.0 & 12.9 & 250 & 435 \\
\hline 280 & 354 & 0.13 & 118 & 140 & 3.7 & 0.3 & 23.5 & 245 & 410 \\
\hline
\end{tabular}

*Determined by $\mathrm{N}_{2}$ physisorption. $\uparrow$ Determined by $\mathrm{NH}_{3} \mathrm{TPD}, \mathrm{T}_{1}$ and $\mathrm{T}_{2}$ are the temperatures at desorption feature maxima. $t$ Determined by pyridine DRIFTS and $\mathrm{NH}_{3}$ TPD.

Figure 2 shows the $\mathrm{NH}_{3}$ TPD profiles for each of the ZSM-5 catalysts of varying SAR. These profiles showed that both an increase in the total acidity and a shift towards higher desorption temperatures with increasing acidity, which are quantified in Table 1. While the total acidity is easily quantified by $\mathrm{NH}_{3} \mathrm{TPD}$, the interpretation of the desorption shape profiles can be complex and detailed analysis may be complicated by several factors such as readsorption and/or slow diffusion, overlapping of comparable strength acid sites, and selection of experimental conditions [23]. Since the experimental 
flows, treatments, and catalyst mass were identical in these experiments, it can be inferred that the shift towards higher desorption temperatures on the lower SAR materials resulted from a slight increase in average acid site strength. Namely, the temperatures at the maximum of the low and high temperature $\mathrm{NH}_{3}$ desorption features $\left(\mathrm{T}_{1}\right.$ and $\mathrm{T}_{2}$, respectively) increase with decreasing SAR, indicating an increase in the acid strength as total acidity increases. Similar trends in desorption temperatures were observed by Lasa and coworkers [24]. X-ray diffraction of the ZSM-5 zeolites was also performed (data not shown), and the expected crystalline structure for ZSM-5 (MFI-type zeolite) was observed on each sample, with no significant differences in the diffraction patterns amongst the materials.

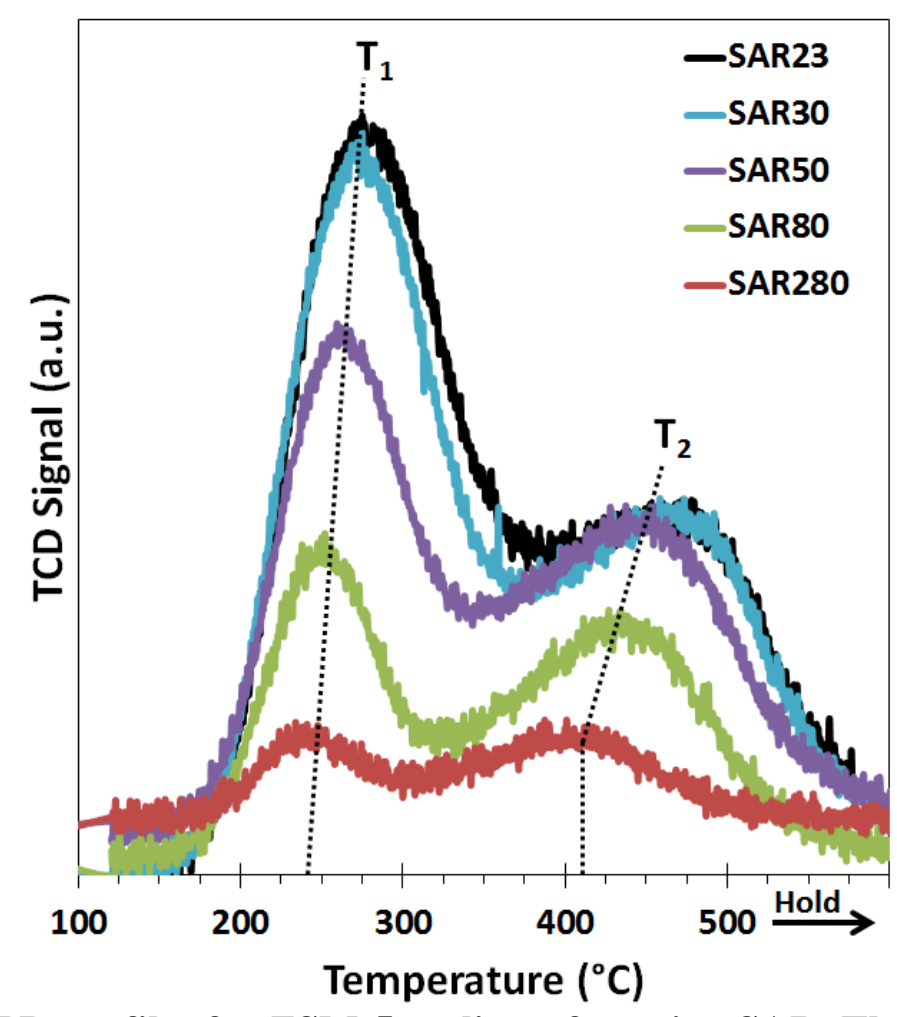

Figure 2. $\mathrm{NH}_{3}$ TPD profiles for ZSM-5 zeolites of varying SAR. The temperature was held at $500^{\circ} \mathrm{C}$ for $30 \mathrm{~min}$.

\subsection{Pyrolysis vapor phase upgrading reactions}

In our previous work, we have shown that the pyrolysis of pine creates a complex mixture of species that can include, among others, organic acids, esters, aldehydes, sugars, propenal, acetone, acetic acid, furans, phenolics, furfural, and substituted aromatics [15]. By passing these vapors over a zeolite catalyst, however, oxygen can be rejected and the variety of species that are detected by GC is greatly reduced, as the fresh ZSM-5 catalysts can selectively produce aromatic hydrocarbons from biomass pyrolysis vapors. As the amount of alumina incorporated in the ZSM-5 zeolites increased, their overall acidity increased, acid site density increased, and the ratio of $\mathrm{B} / \mathrm{L}$ acid sites decreased, as shown in Table 1. To understand the effects of the nominal acidity on the both the yield and selectivity of aromatic hydrocarbons during upgrading of biomass 
pyrolysis vapors, five ZSM-5 catalysts of varying acidity ( $\mathrm{SAR}=23,30,50,80$, and 280) were evaluated.

Figure 3 shows the averaged chromatograms for primary pine pyrolysis vapors and pine pyrolysis vapors upgraded over ZSM-5 catalysts of varying acidity. When the pine was pyrolyzed in the absence of a catalyst, a complex mixture of products was observed in agreement with our previously reported study [17]. Major oxygenated compounds observed without the catalyst included acetic acid, furfural, methyl furan, methyl phenols, and guaiacol. When a ZSM-5 catalyst was introduced there was a marked increase in the intensity of peaks associated with aromatic hydrocarbons (Table 2), which were absent when no catalyst was used. Additionally, as the ZSM-5 SAR decreased (increasing acidity), the number of peaks associated with oxygenated pyrolysis products decreased. The formation of the larger, alkylated compounds (e.g., trimethyl benzene, alkylated naphthalene, and alkylated anthracene) over the ZSM-5 catalysts, which are used for their shape selectivity, are likely to occur on the external zeolite surfaces due to steric constraints which would limit the ability of these products to form and diffuse through the zeolite micropore system [25].

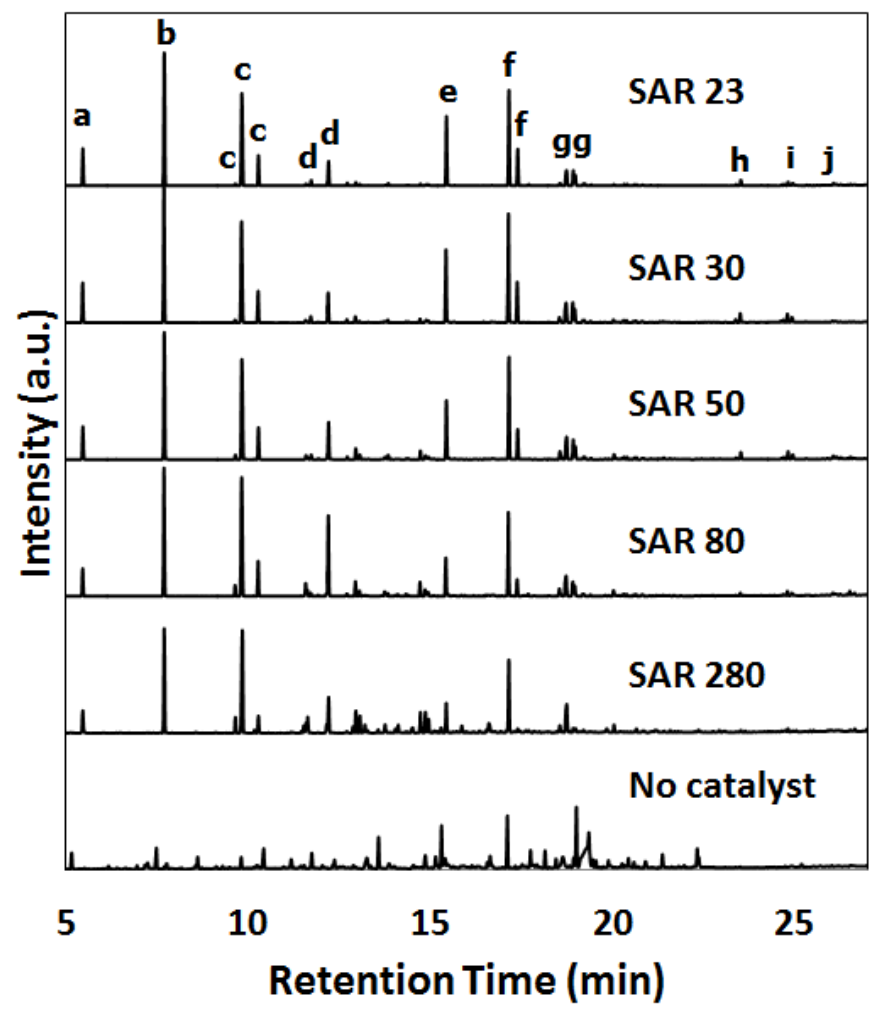

Figure 3. Averaged gas chromatograms for upgraded pine pyrolysis vapors at $5^{500}{ }^{\circ}$ over ZSM-5 of varying SAR. Peaks labeled a-j are identified in Table 2.

Table 2. Aromatic hydrocarbons identified by GCMS during upgrading of pine pyrolysis vapors from Figure 3 .

\begin{tabular}{|c|c|c|c|}
\hline Label & Compound & Structure & $\begin{array}{c}\text { Approx. GC } \\
\text { Retention Time(s), } \\
\text { min. }\end{array}$ \\
\hline
\end{tabular}




\begin{tabular}{|c|c|c|}
\hline $\mathrm{a}$ & Benzene & 5.46 \\
\hline b & Toluene & 7.70 \\
\hline $\mathrm{c}$ & Xylenes; ethyl benzene & $9.64,9.83,10.28$ \\
\hline$d$ & $\begin{array}{l}\text { Trimethyl benzenes; } \\
\text { methyl ethyl benzene }\end{array}$ & $11.72,12.20$ \\
\hline $\mathrm{e}$ & Naphthalene & 15.42 \\
\hline $\mathrm{f}$ & Methyl naphthalenes & $17.15,17.39$ \\
\hline $\mathrm{g}$ & Dimethyl naphthalenes & $18.73,18.91$ \\
\hline h & Anthracene & 23.51 \\
\hline $\mathrm{i}$ & Methyl anthracenes & $24.79,24.92$ \\
\hline $\mathrm{j}$ & Dimethyl anthracenes & 26.06 \\
\hline
\end{tabular}

Figure 4 shows the total aromatic hydrocarbons produced during biomass pyrolysis upgrading over the ZSM-5 catalysts of varying SAR, as well as the individual contributions from each family of 1-ring, 2-ring, and 3-ring aromatic compounds. There was an increase in the overall yield of aromatics with increasing acidity, up until an acidity of $1120 \mu \mathrm{mol} / \mathrm{g}$ (corresponding to SAR = 30). The SAR = $30 \mathrm{ZSM}-5$ produced the maximum amount of aromatics, while the more acidic zeolite (SAR $=23$ ) showed a decrease in the overall yield of aromatics. This optimum aromatic productivity was previously observed for the catalytic upgrading of glucose over a ZSM-5 zeolite with $\mathrm{SAR}=30$ [26]. One possible explanation for an optimal level of acidity for producing aromatic hydrocarbons is that the decrease in the average distance between acid sites (with increasing SAR) promotes secondary reactions that preferentially form aromatic compounds within the zeolite micropores. When acid sites become too close to one another, however, reactions that lead to the formation of coke are more favorable and lead to a decrease in aromatic production [26], which was observed on the most acidic sample ( $\mathrm{SAR}=23$, see Fig. 4). The most significant increase in aromatic production was observed for the 1-ring and 2-ring aromatic compounds when moving from the lowest acidity catalyst $(\mathrm{SAR}=280)$ to the catalyst with moderate acidity $(\mathrm{SAR}=50)$, which corresponded to a six-fold increase in acid site density. In addition, the production of 2and 3-ring aromatic compounds increased with increasing catalyst acidity. This further suggests that there is an optimal spacing between acid sites that promotes the formation of aromatic compounds, and the optimal distance depends on the type of species to be formed (i.e., 1-, 2-, or 3-ring aromatics). 


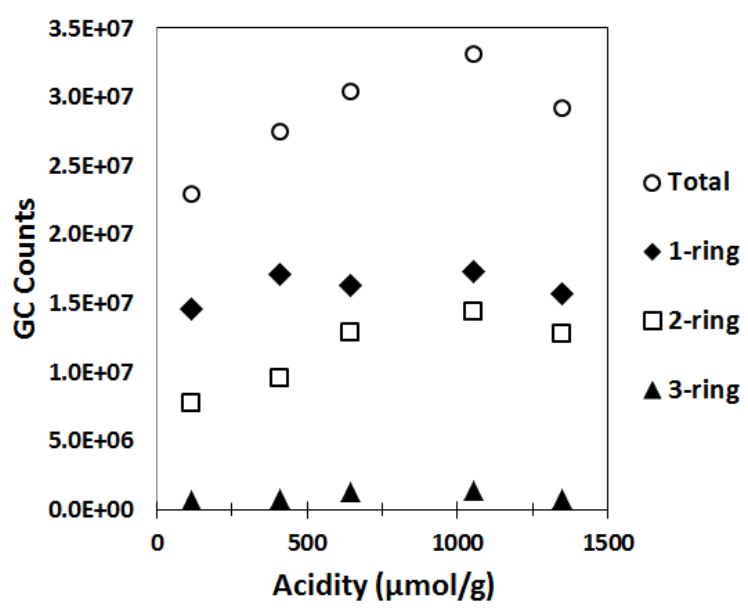

Figure 4. GC counts for detected aromatic hydrocarbons (grouped by 1-ring, 2-ring, or 3-ring aromatic compounds) during upgrading of pyrolysis vapors over ZSM-5 zeolites of varying acidity.

The selectivity towards aromatic compounds as a function of ZSM-5 SAR within the 1-ring, 2-ring, and 3-ring families, as well as the ratio of substituted-to-unsubstituted products, is shown in Figure 5. In looking at the 1-ring aromatics (Fig. 5a), the selectivity towards benzene increased with increasing catalyst acidity. This increase in benzene selectivity was accompanied by a corresponding decrease in selectivity towards dimethyl benzene (xylene) and trimethyl benzene. The toluene selectivity also increased with increasing catalyst acidity until SAR $=30(1120 \mu \mathrm{mol} / \mathrm{g})$, at which point the increase in acidity did not enhance toluene selectivity. The interconversion of aromatics by alkyl transfer reactions could explain the changes in product selectivity, as it is possible that the di- and tri-substituted 1-ring aromatics (i.e., xylene and trimethyl benzene) undergo disproportionation reactions to form toluene and/or benzene [27]. These types of disproportionation reactions could contribute to the increase in observed toluene and benzene selectivity with increasing acidity. Another possible explanation could be that the increased proximity of acid sites to each other promotes reactions that lead to a higher degree of cyclization rather than alkyl addition and transalkylation reactions.
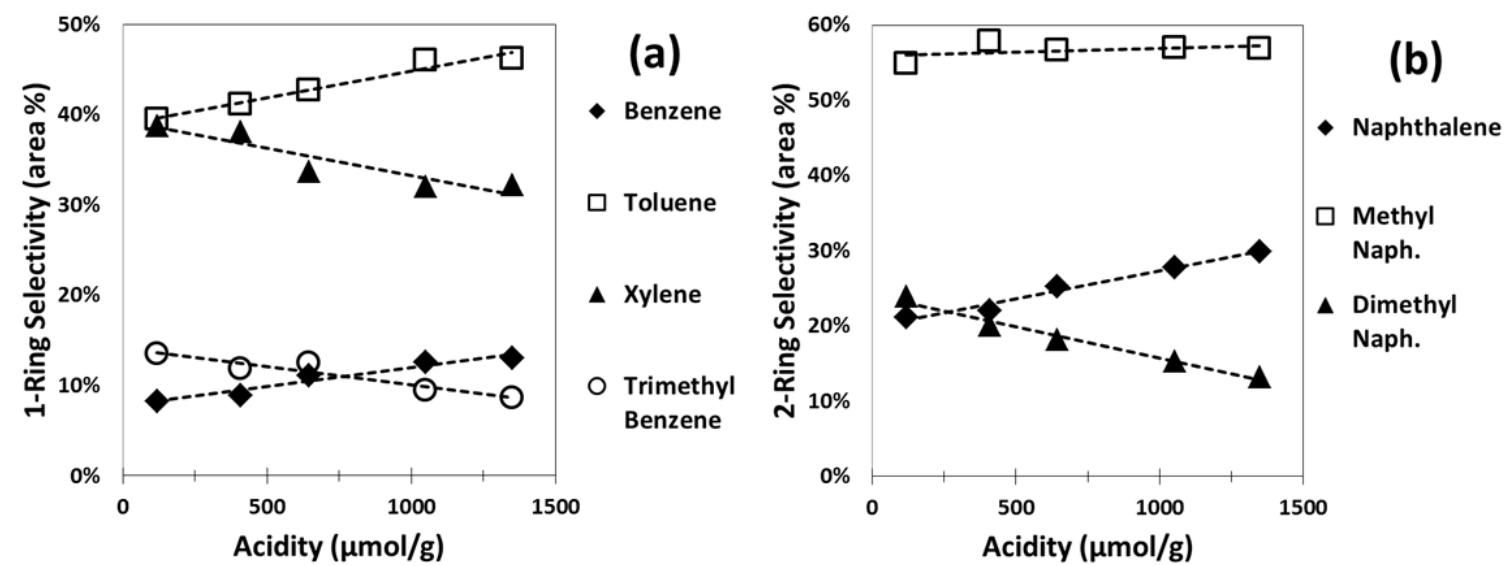

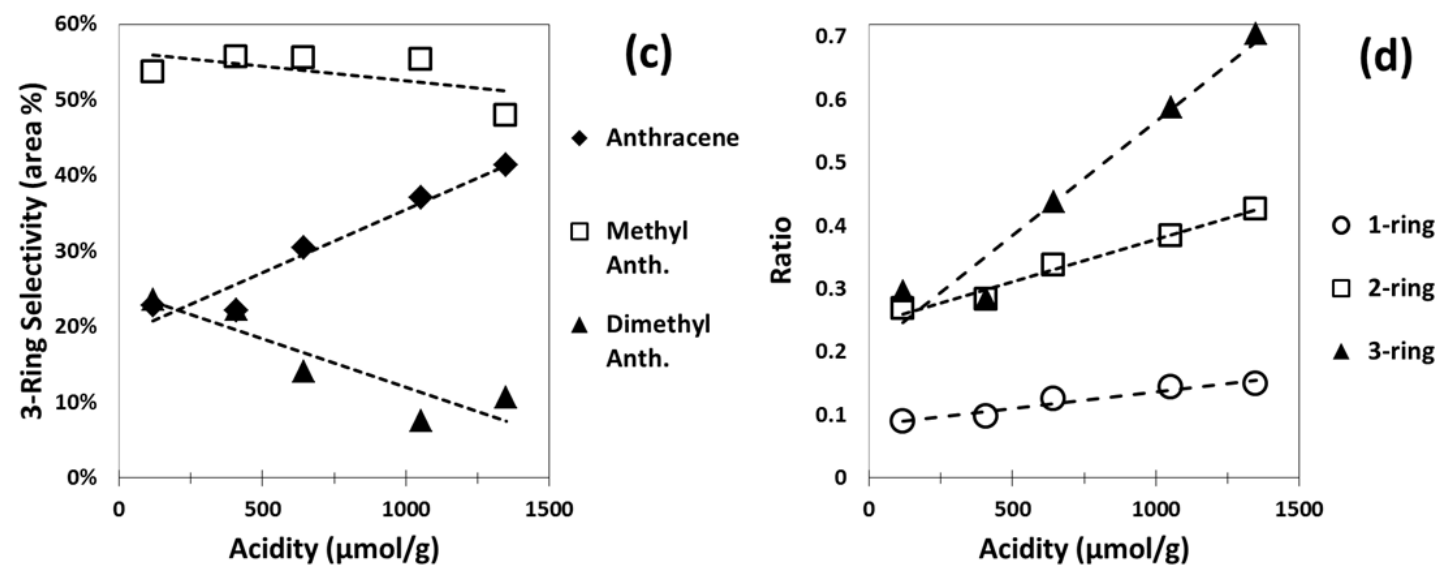

Figure 5. Product selectivity within each family of (a) 1-ring, (b) 2-ring, and (c) 3ring aromatic compounds during vapor upgrading over ZSM-5 catalysts of varying acidity and (d) the corresponding ratio of unsubstituted-to-substituted aromatic compounds within each class of 1-ring, 2-ring, and 3-ring compounds as a function of catalyst acidity. Lines on graphs are linear regression fits.

The selectivity amongst 2-ring aromatics (Fig. 5b) shows similar overall trends as for the 1-ring aromatics. Namely, the dimethyl naphthalene selectivity decreased, while naphthalene selectivity increased with increasing catalyst acidity, and the methyl naphthalene selectivity remained nearly constant. The selectivity of the 3-ring aromatics showed the same trends as the 1-ring and 2-ring compounds, i.e., an increase in selectivity to anthracene and a decrease in the dimethyl anthracene selectivity with increasing acidity were observed (Fig. 5c). The commonality for each family of aromatic compounds (i.e., 1-, 2-, and 3-ring) is that the selectivity towards unsubstituted products increases with increasing catalyst acidity. This trend is shown in Figure 5d where the ratio of unsubstituted-to-substituted products increases with an increase in catalyst acidity.

To differentiate if the changes in product selectivity are due to a change in the primary products that are formed or interconversion of aromatic compounds by alkyl transfer reactions (e.g., disproportionation and transalkylation), we examined the degree of substitution of the products. If alkyl groups were transferred amongst aromatic compounds, the overall degree of substitution would be expected to remain constant, and not correlate with zeolite acidity. Comparing the degree of substitution (Fig. 5a-c) and ratio of unsubstituted-to-substituted aromatic compounds (Fig. 5d), and accounting for individual alkyl group contributions (i.e., xylene corresponds to two methyl groups whereas toluene accounts for one methyl group), the ratio of unsubstituted-to-substituted aromatics is clearly increasing with an increase in acidity. In other words, the degree of aromatic substitution decreases with increasing acidity. These data, therefore, suggest that the while transalkylation reactions may occur within the zeolites, the changes in product selectivity that were observed are due to differences in the formation of the primary aromatic compounds. As the acid site density increases and spacing between acid sites decreases, the reactions within the zeolite micropores that are responsible for the formation of unsubstituted aromatic compounds increase at a faster rate than alkyl addition reactions. 
Finally, it is interesting to note that while the mono-methylated aromatic compounds were the most selective products in each ring family for all of the ZSM-5 catalysts tested, the relative improvement in selectivity to the unsubstituted products was greatly increased when moving from the least to most acidic zeolite. Compared to the selectivity obtained on the least acidic ZSM-5 $(\mathrm{SAR}=280)$, the selectivity for benzene, naphthalene, and anthracene increased by $60 \%, 40 \%$, and $80 \%$, respectively, when using the most acidic ZSM-5 (SAR = 23). If highly substituted aromatics are desired, lower acid site density ZSM-5 zeolites are preferable. Conversely, if unsubstituted aromatic compounds (e.g., benzene, naphthalene, anthracene) are preferred, a ZSM-5 zeolite with higher acid site density can be used to shift the product selectivity accordingly. Scheme 1 depicts how the relative catalyst acidity affects the slate of aromatic compounds, in terms of the degree of substitution, that are produced during VPU of biomass pyrolysis vapors.

\section{Scheme 1. Conversion of primary oxygenated pyrolysis products to aromatic hydrocarbons over ZSM-5 catalysts.}

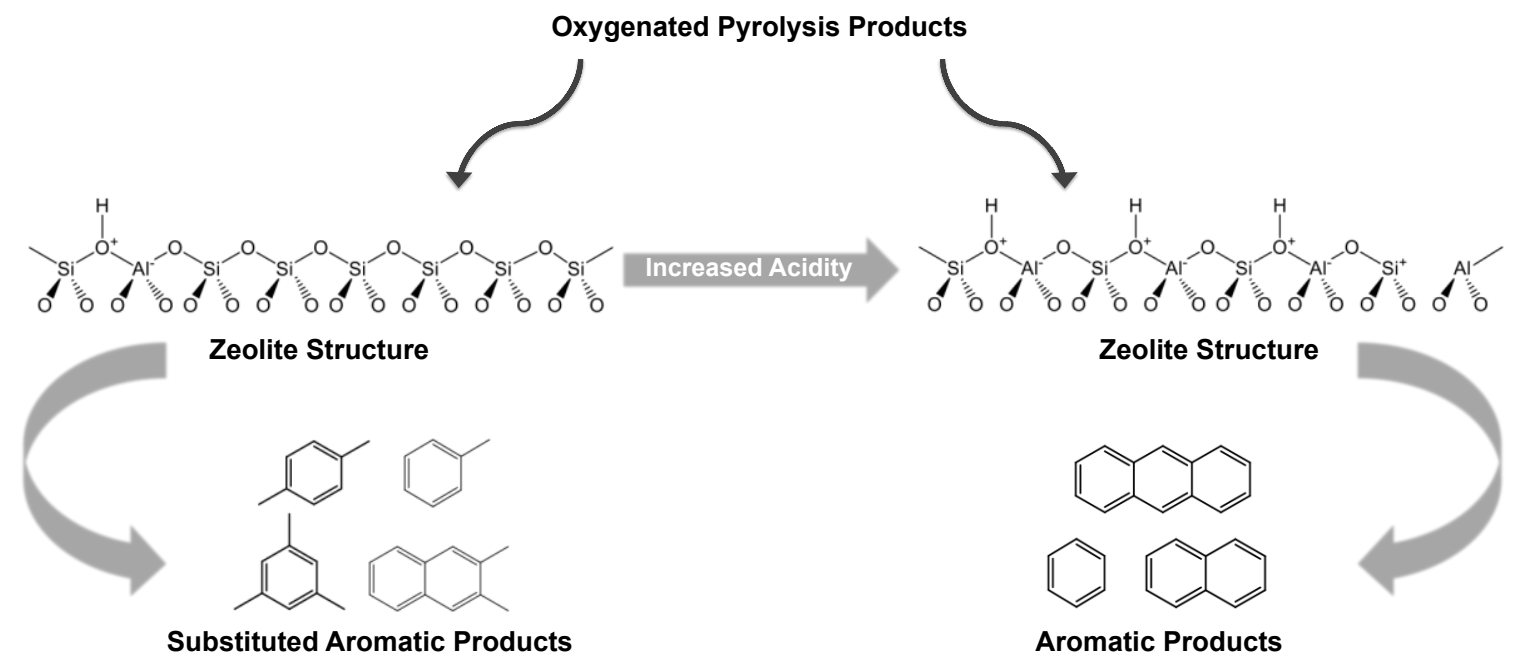

\subsection{Conclusions}

Catalytic upgrading of biomass pyrolysis vapors to create deoxygenated aromatic hydrocarbons is a process that generates useful intermediates that can be integrated seamlessly with traditional fuel and chemical production platforms (Scheme 1). The acid sites within the well-defined pore structures of zeolites are known to be responsible for the formation of aromatics, and this study aimed to investigate how the acidity of a ZSM5 catalyst affects the selectivity towards different aromatic compounds.

Pine pyrolysis vapors were upgraded at $500^{\circ} \mathrm{C}$ over ZSM- 5 catalysts of SAR $=$ $23,30,50,80$, and 280 to produce deoxygenated aromatic compounds consisting of 1-, 2, and 3-ring aromatic compounds. The overall yield of aromatics increased with increasing ZSM-5 acidity, until a maximum was observed when using a ZSM-5 catalyst with a SAR $=30$. The increase in acidity beyond $\mathrm{SAR}=30$ led to decreased aromatic production, which was attributed to the formation of polyaromatic compounds that were associated with coke forming precursors. This observation was consistent with the 
experimental finding that the selectivity towards polycyclic aromatic compounds (i.e., 2and 3-ring) increased with increasing ZSM-5 acidity. Additionally, the degree of substitution for all three families of aromatic hydrocarbons (1-, 2-, and 3-ring) decreased as catalyst acidity increased. The increase in selectivity towards unsubstituted aromatics with increasing acidity can be explained by the rate cyclization reactions increasing faster relative to transalkylation reactions as acid site density increases. By understanding how aromatic product selectivity is affected by ZSM-5 zeolites of varying acidity, the relative amounts of substituted and polycyclic aromatic compounds can be adjusted in order to maximize yield of the higher-value products.

\section{Acknowledgements}

The authors would like to thank the U.S. Department of Energy's Bioenergy Technologies Office (DOE-BETO) for supporting this work under Contract No. DEAC36-08GO28308, as well as the Science Undergraduate Laboratory Internships (SULI) program under the U.S. DOE's Office of Science.

\section{References}

[1] R. French, S. Czernik, Fuel Process. Technol. 91 (2010) 25-32.

[2] P.M. Mortensen, J.D. Grunwaldt, P.A. Jensen, K.G. Knudsen, A.D. Jensen, Appl. Catal. A 407 (2011) 1-19.

[3] A.V. Bridgwater, Biomass Bioenerg. 38 (2012) 68-94.

[4] M.S. Talmadge, R.M. Baldwin, M.J. Biddy, R.L. McCormick, G.T. Beckham, G.A. Ferguson, S. Czernik, K.A. Magrini-Bair, T.D. Foust, P.D. Metelski, C. Hetrick, M.R. Nimlos, Green Chem. 16 (2014) 407-453.

[5] S. Wan, Y. Wang, Front. Chem. Sci. Eng. 8 (2014) 280-294.

[6] G.W. Huber, S. Iborra, A. Corma, Chem. Rev. 106 (2006) 4044-4098.

[7] D. Mohan, C.U. Pittman, P.H. Steele, Energ. Fuel 20 (2006) 848-889.

[8] J. Jae, R. Coolman, T.J. Mountziaris, G.W. Huber, Chem. Eng. Sci. 108 (2014) 33-46.

[9] V. Paasikallio, C. Lindfors, E. Kuoppala, Y. Solantausta, A. Oasmaa, J. Lehto, J.

Lehtonen, Green Chem. 16 (2014) 3549.

[10] M. Guisnet, P. Magnoux, Catal. Today 36 (1997) 477-483.

[11] E. Gürbüz, J.Q. Bond, J.A. Dumesic, Y. Román-Leshkov, Role of Acid Catalysis in the Conversion of Lignocellulosic Biomass to Fuels and Chemicals, in: K.S.

Triantafyllidis, A.A. Lappas, M. Stöcker (Eds.), The Role of Catalysis for the Sustainable Production of Bio-fuels and Bio-chemicals, Elsevier, Amsterdam, 2013, pp. 261-288.

[12] J.F. Haw, Phys. Chem. Chem. Phys. 4 (2002) 5431-5441.

[13] K.K. Ramasamy, Y. Wang, Catal. Today 237 (2014) 89-99.

[14] C. Hansch, Chem. Rev. 53 (1953) 353-396.

[15] C. Mukarakate, M.J. Watson, J. ten Dam, X. Baucherel, S. Budhi, M.M. Yung, H.

Ben, K. Iisa, R.M. Baldwin, M.R. Nimlos, Green Chem. 16 (2014) 4891-4905.

[16] S. Wan, C. Waters, A. Stevens, A. Gumidyala, R. Jentoft, L. Lobban, D. Resasco, R. Mallinson, S. Crossley, ChemSusChem 8 (2015) 552-559. 
[17] C. Mukarakate, X. Zhang, A.R. Stanton, D.J. Robichaud, P.N. Ciesielski, K. Malhotra, B.S. Donohoe, E. Gjersing, R.J. Evans, D.S. Heroux, R. Richards, K. Iisa, M.R. Nimlos, Green Chem. 16 (2014) 1444-1461.

[18] S. Brunauer, P. Emmett, E. Teller, J. Am. Chem. Soc. 60 (1936) 309-319.

[19] E.P. Barrett, L.G. Joyner, P.P. Halenda, J. Am. Chem. Soc. 73 (1951) 373-380.

[20] S.M. Maier, A. Jentys, J.A. Lercher, J. Phys. Chem. C 115 (2011) 8005-8013.

[21] P.L. Benito, A.G. Gayubo, A.T. Aguayo, M. Olazar, J. Bilbao, J. Chem. Tech.

Biotechnol. 66 (1996) 183-191.

[22] J. Datka, E. Tuznik, J. Catal. 102 (1986) 43-51.

[23] L. Rodríguez-González, F. Hermes, M. Bertmer, E. Rodríguez-Castellón, A.

Jiménez-López, U. Simon, Appl. Catal. A-Gen. 328 (2007) 174-182.

[24] A.S. Al-Dughaither, H. de Lasa, Ind. Eng. Chem. Res. 53 (2014) 15303-15316.

[25] O. Cappellazzo, G. Cao, G. Messina, M. Morbidelli, Ind. Eng. Chem. Res. 30 (1991) 2280-2287.

[26] A.J. Foster, J. Jae, Y.-T. Cheng, G.W. Huber, R.F. Lobo, Appl. Catal. A-Gen. 423424 (2012) 154-161.

[27] T.-C. Tsai, S.-B. Liu, I. Wang, Appl. Catal. A 181 (1999) 355-398. 